\title{
Seventy Five
}

National Cancer Institute

\section{Source}

National Cancer Institute. Seventy Five. NCI Thesaurus. Code C160687.

A natural number greater than seventy-four and less than seventy-six and the quantity that it denotes. 